AUTHORS:

Madelien Wooding ${ }^{1}$

Justin Bradfield2,3

Vinesh Maharaj ${ }^{1}$

Dwayne Koot ${ }^{1}$

Lyn Wadley ${ }^{3}$ iD

Linda Prinslo0 $0^{4,5}$ iD

Marlize Lombard² (iD

\section{AFFILIATIONS:}

'Department of Chemistry, University of Pretoria, Pretoria,

South Africa

2Department of Anthropology and Development Studies, University of Johannesburg, Johannesburg, South Africa

${ }^{3}$ Evolutionary Studies Institute, School of Geosciences,

University of the Witwatersrand Johannesburg, South Africa

${ }^{4}$ Department of Physics,

University of Pretoria, Pretoria,

South Africa

${ }^{5}$ Centre for Archaeological Science, School of Earth

and Environmental Sciences, University of Wollongong,

Sydney, Australia

CORRESPONDENCE TO: Justin Bradfield

EMAIL:

Jbradfield8@gmail.com

DATES:

Received: 14 July 2016

Revised: 21 Oct. 2016

Accepted: 02 Nov. 2016

\section{KEYWORDS:}

San hunting poisons;

southern Africa;

liquid chromatography; accurate mass-mass spectrometry; archaeological analysis

\section{HOW TO CITE:}

Wooding M, Bradfield J,

Maharaj V, Koot D, Wadley L,

Prinsloo L, et al. Potential for

identifying plant-based toxins on

San hunter-gatherer arrowheads.

S Afr J Sci. 2017;113(3/4),

Art. \#2016-0210, 10 pages.

http://dx.doi.org/10.17159/

sajs.2017/20160210

\section{ARTICLE INCLUDES:}

$\times$ Supplementary material

$\times$ Data set

\section{FUNDING:}

National Research Foundation (South Africa)

(c) 2017. The Author(s). Published under a Creative

Commons Attribution Licence.

\title{
Potential for identifying plant-based toxins on San hunter-gatherer arrowheads
}

\begin{abstract}
The antiquity of the use of hunting poisons has received much attention in recent years. In this paper we present the results of a pilot study designed to detect the presence of organic compounds, typically of less than $1200 \mathrm{Da}$, from poisonous plants that may have been used as hunting poisons in the past. We used ultra-performance liquid chromatography connected to a Synapt G2 high-resolution MS-QTOF mass spectrometer (UPLC-QTOF-MS) to provisionally identify plant-based toxins present in (1) extracts of fresh plant material, (2) a blind control recipe consisting of three plant ingredients and (3) a Hei| |om arrow poison of unknown ingredients. Although not all expected toxic compounds were identified, those that were identified compared favourably with those reported in the literature and confirmed through databases, specifically the Dictionary of Natural Products and ChemSpider. MS/MS fragmentation patterns and accurate mass were used for tentative identification of compounds because archaeological residues usually contain insufficient material for unambiguous identification using nuclear magnetic resonance. We highlight the potential of this method for accurately identifying plant-based toxins present on archaeological artefacts and unique (albeit non-toxic) chemical markers that may allow one to infer the presence of toxic plant ingredients in arrow poisons. Any chemical study of archaeological material should consider the unique environmental degradative factors and be sensitive to the oxidative byproducts of toxic compounds.
\end{abstract}

\section{Significance:}

- Methodology is presented for the identification of ancient plant-based arrow poisons.

\section{Introduction}

Bow hunting with poisoned arrows is well documented among southern African San hunter-gatherers. ${ }^{1-3}$ Less well known is the great variety of toxic plants that were - or could have been - used for this purpose. ${ }^{4-6}$ Most chemistry studies in which the ingredients of San poison arrows have been investigated focused on the more commonly known Chrysomelidae family of leaf beetle, which includes the Diamphidia and Polyclada genera. ${ }^{7-10}$ Few studies thus far have been devoted specifically to plant poison ingredients, ${ }^{11,12}$ and most of these studies are now several decades old. Now with the availability of new, more advanced, sensitive and reliable chemical detection techniques, we may be able to identify plant-based toxins present on archaeological artefacts.

Among the Kalahari San, large game is hunted with a bow and poisoned arrows ${ }^{2,13}$ (Figure 1). This practice is widely considered to extend back at least 12000 years, ${ }^{14}$ but might be considerably older ${ }^{15}$. The identification of bow and arrow hunting systems can highlight aspects of technological complexity and past cognition. ${ }^{16,17}$ More subtle innovations within hunting systems, such as the introduction of poisons, also have potential to inform on past cognitive frameworks and the time-depth of indigenous knowledge systems. ${ }^{4}$ However, tracing such technobehaviours through the Stone Age is not an easy task. The interpretation of bone artefacts as arrow components from 37000 year-old levels at White Paintings Shelter ${ }^{18}, 43000$ year-old levels at Border Cave ${ }^{15}$ and $>61000$ years ago at Sibudu ${ }^{19}$ pushes back in time the probable invention of bow and arrow hunting. This inference is corroborated by the functional interpretations of small quartz artefacts from Sibudu and Umhlatuzana dating to between 65000 and 60000 years ago. ${ }^{20-23}$ The great antiquity of the use of certain toxic plants to poison arrows is purported from 24000 -year-old levels at Border Cave, KwaZulu-Natal, South Africa. ${ }^{15} \mathrm{At}$ this site, the remains of ricinoleic acid - an oxidative by-product of ricin - were discovered on a wooden stick, morphologically similar to 20th-century San arrow poison applicators. ${ }^{15}$ Even earlier than this discovery, at approximately 77000 years ago, people at Sibudu Cave (KwaZulu-Natal) constructed their bedding from plants with natural insecticidal and larvicidal properties ${ }^{24}$, implying a practical understanding of the biochemical properties of certain plants.

In this paper we build on the growing interest in ancient poison chemical characterisation ${ }^{25}$ and present the results of a pilot study designed to detect the presence of small organic compounds, typically of less than $1200 \mathrm{Da}$ (mass in Dalton units), from poisonous plants. An ultra-performance liquid chromatography system coupled to a Synapt G2 quadrupole time-of-flight mass spectrometer (UPLC-QTOF-MS) was used provisionally to identify known toxic compounds through comparison of their accurate masses to those recorded in databases (such as ChemSpider and Dictionary of Natural Products) for 11 of the most commonly occurring toxic plants reported in the southern African literature. Poison from a 100-year-old bone arrow from northern Namibia as well as a blind control poison recipe were subsequently analysed as a proof of concept using the same technique. We highlight the potential of this method for accurately identifying plant-based toxins present on archaeological artefacts.

\section{Background}

A diverse group of organic compounds known as secondary metabolites is produced by plants. Secondary metabolites defend plants against a variety of pathogens and herbivore ${ }^{26}$ and are of great importance for medicinal drugs, industrial materials and poisons ${ }^{27}$. 


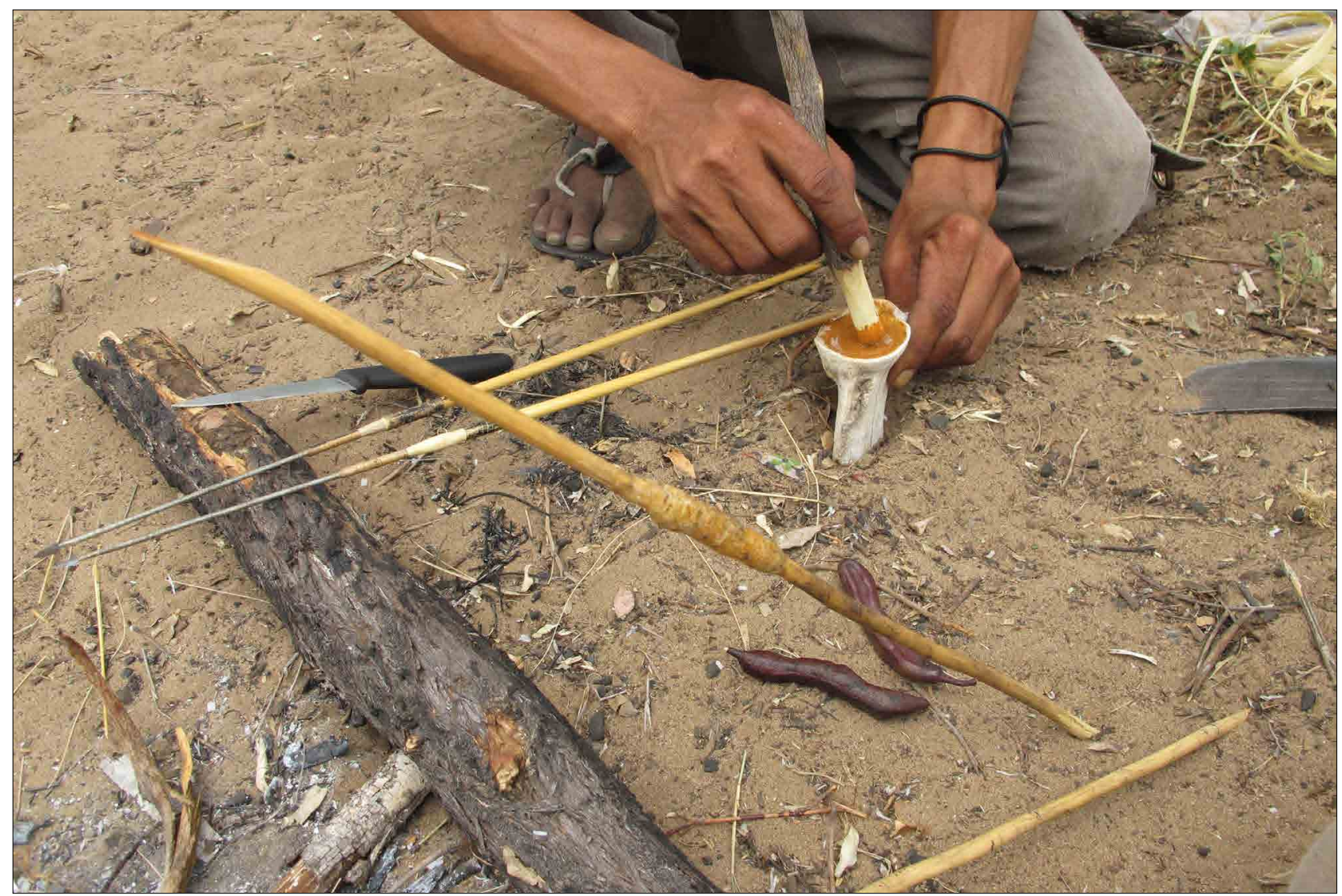

Photo: CLyn Wadley

Figure 1: Ju/'hoan hunter in a Nyae Nyae village mixing poison in a hollow bone. The poison is applied to the new arrowheads lying in front of him. Swartzia madagascariensis pods are next to the glue stick/poison applicator.

Alkaloids, terpenoids and cardiotonic glycosides, the main secondary metabolite compounds responsible for the toxicity of arrow poisons ${ }^{26,28}$, are regularly used in small doses for their medicinal qualities in modern pharmaceuticals ${ }^{29,30}$ and have a long history of ethnopharmacological use $^{12}$. Although currently much is known about the active toxins in some southern African flora species ${ }^{12,26}$, many species remain insufficiently studied ${ }^{4}$. In some cases, studies have focused only on certain parts of plants such as the leaves or fruit rather than the sap and roots. Chemical compounds are distributed differently throughout the plant ${ }^{29}-$ a phenomenon of which the San were aware, as they would only use the toxic parts such as the sap of succulent plants ${ }^{4,12}$.

San hunters sometimes included additives with their arrow poison. A variety of reasons for this practice has been offered, for example, to increase the viscosity of the mixture to aid adhesion and to enhance the efficacy of the poison. ${ }^{30,31}$ The additives result in complex recipes containing multiple organic components derived from different sources, ${ }^{4}$ which makes trying to identify specific toxins in a sample of ancient poison challenging. Not only will one expect to see the by-products of the oxidative breakdown of the toxic compounds, but identification will be complicated by the combination of numerous compounds. ${ }^{25}$

Archaeological samples can be divided into inorganic materials and organic materials. Inorganic materials include stone tools, pottery and metal artefacts. Organic materials can include plant and animal remains as well as their deteriorative and biotransformative products. Inorganic materials are generally better preserved than organic materials. Preservation of organic materials such as plant toxins is significantly affected by environmental factors, such as soil pH, temperature, oxygen, moisture exposure and substrate, especially if the sample has been exposed to these factors over extended periods of time. ${ }^{32}$ The rate of decomposition of organic compounds is variable depending on the class and structural type. For example, sugars, starches and simple proteins may decompose at a faster rate than lignins and phenolic compounds. As such, phytochemical residues present on archaeological artefacts may not perfectly resemble a freshly extracted phytochemical profile of the parent compound. Any chemical study of archaeological material should therefore consider the oxidative by-products of toxic compounds, which further complicate the analyses as a result of the complex matrix.

\section{Materials and methods}

\section{Sample preparation}

\section{Eleven South African plants}

Eleven plants were selected for this study based on previously reported studies that show them to contain toxic compounds of known chemical structures, and therefore with known molecular formulae (Table 1). Fresh plants were collected mainly from the Walter Sisulu National Botanical Gardens and the parts traditionally used for poison preparation by the $\mathrm{San}^{4}$ were air dried and used for the analysis.

\section{Blind test on the control sample}

The second part of our study involved a blind test. A poison mixture was prepared in the laboratory, mimicking a known San poison recipe. This recipe, consisting of three poisonous plant ingredients, was prepared in accordance with historical San practices. ${ }^{4,11}$ The ingredients of this recipe were known to only one author $(\mathrm{JB})$, and the sample was prepared as follows:

1. The stem and leaves of Acokanthera oppositifolia were boiled in water for $8 \mathrm{~h}$ until a yellow viscid fluid was obtained.

2. Once cooled, the latex of Euphorbia tirucalli was added. 
3. To this mixture was added the juice of Adenium multiflorum, which was obtained by heating a branch of $A$. multiflorum over a fire until the juices oozed out of the cut end.

4. The ingredients were collected in a glass Petri dish and mixed.

5. The resulting beige liquid was applied to replica stone and bone artefacts and left in the sun to dry for $24 \mathrm{~h}$.

6. Once dry, the consistency was that of a hard resin.

These 'tools' were chemically analysed approximately 2 weeks after preparation.

\section{Analysis of poison on a Hei | | om arrow}

The third part of our study was the examination of a poison sample of unknown chemistry taken from a Hei| Iom arrow, purportedly collected by Dr Louis Fourie ${ }^{33,34}$ in Namibia ${ }^{35,36}$. This arrow, made available by Museum Africa to JB, is unaccessioned, but was found with the Fourie collection and is identical to the rest of the Hei| | om bone-tipped arrows. It is considered to be of equivalent age ( \pm 90 years), and most likely part of the same collection.

\section{Extraction, isolation and analysis}

\section{Eleven South African plants}

Each plant sample was extracted, isolated and analysed in the same way. Each plant was air dried and ground to a fine powder. An amount of $1 \mathrm{~g}$ of the dried powdered plant material was extracted by stirring for $1 \mathrm{~h}$ with $10 \mathrm{~mL}$ of dichloromethane:methanol (DCM:MeOH, 1:1). The extraction solvents were of analytical grade and purchased from Fluka. The extraction was repeated twice and filtered through Whatman filter paper no. 1 before pooling of the solvent extracts. The extracts were dried under reduced pressure below $40^{\circ} \mathrm{C}$ using a rotary evaporator. Samples were stored dry in a temperature-controlled room at $23^{\circ} \mathrm{C}$ prior to analysis.

\section{Blind control sample}

The replicated stone and bone artefacts held only small quantities of poison. Therefore $1 \mathrm{~mL}$ of $\mathrm{DCM}: \mathrm{MeOH}$ (1:1) was added directly to the containers holding the poison. Extraction was done by ultrasonication of the mixture for $30 \mathrm{~min}$. The extract was filtered and solvents were removed in vacuo. Samples were stored in a temperature-controlled room $\left(23^{\circ} \mathrm{C}\right)$ prior to analysis.

Table 1: $\quad$ Fresh plant samples listing the reported toxins and their accurate mass

\begin{tabular}{|c|c|c|c|c|}
\hline Sample \# & Plant name & Plant parts used & Type of toxin & Toxic compound \\
\hline$M W-1-4 A$ & $\begin{array}{l}\text { Acokanthera oppositifolia } \\
\text { (Bushman's poison) }\end{array}$ & Leaves and stem & Cardiac glycoside & $\begin{array}{l}\text { Ouabain }\left(\mathrm{C}_{29} \mathrm{H}_{44} \mathrm{O}_{12}\right) \\
\text { Acovenoside } \mathrm{A}\left(\mathrm{C}_{30} \mathrm{H}_{46} \mathrm{O}_{9}\right)\end{array}$ \\
\hline$M W-1-2 B$ & $\begin{array}{l}\text { Adenium multiflorum } \\
\text { (Impala lily) }\end{array}$ & Stem & Cardiac glycoside & $\begin{array}{l}\text { Obebioside } \mathrm{B}\left(\mathrm{C}_{38} \mathrm{H}_{58} \mathrm{O}_{15}\right) \\
\text { Hongheloside } \mathrm{B}\left(\mathrm{C}_{36} \mathrm{H}_{56} \mathrm{O}_{14}\right) \\
\text { Tetraphyllin } \mathrm{B}\left(\mathrm{C}_{12} \mathrm{H}_{17} \mathrm{NO}_{7}\right)\end{array}$ \\
\hline$M W-1-3 C$ & Aloe gariepensis & Sap & & $\begin{array}{l}\mathrm{V} \text {-Coniceine }\left(\mathrm{C}_{8} \mathrm{H}_{15} \mathrm{~N}\right) \\
\text { Conhydrine }\left(\mathrm{C}_{8} \mathrm{H}_{17} \mathrm{NO}\right)\end{array}$ \\
\hline$M W-1-3 F$ & Aloe globuligemma & Sap & Piperidine & $\begin{array}{l}\text { Coniine }\left(\mathrm{C}_{8} \mathrm{H}_{17} \mathrm{~N}\right) \\
\text { Conhydrine }\left(\mathrm{C}_{8} \mathrm{H}_{17} \mathrm{NO}\right)\end{array}$ \\
\hline$M W-1-3 A$ & $\begin{array}{l}\text { Ammocharis coranica } \\
\text { (Karoo lily) }\end{array}$ & Bulb & Isoquinoline alkaloid & $\begin{array}{l}\text { Lycorine }\left(\mathrm{C}_{16} \mathrm{H}_{17} \mathrm{NO}_{4}\right) \\
\text { Caranine }\left(\mathrm{C}_{16} \mathrm{H}_{17} \mathrm{NO}_{3}\right) \\
\text { Crinamine }\left(\mathrm{C}_{17} \mathrm{H}_{19} \mathrm{NO}_{4}\right) \\
\text { Acetylcaranine }\left(\mathrm{C}_{18} \mathrm{H}_{19} \mathrm{NO}_{4}\right)\end{array}$ \\
\hline$M W-1-2 A$ & $\begin{array}{l}\text { Boophane disticha } \\
\text { (Poison bulb) }\end{array}$ & Bulb & Isoquinoline alkaloid & $\begin{array}{l}\text { Haemanthamine/Crinamine }\left(\mathrm{C}_{17} \mathrm{H}_{19} \mathrm{NO}_{4}\right) \\
\text { Lycorine }\left(\mathrm{C}_{16} \mathrm{H}_{17} \mathrm{NO}_{4}\right) \\
\text { Buphanine }\left(\mathrm{C}_{18} \mathrm{H}_{21} \mathrm{NO}_{4}\right) \\
\text { Crinamidine }\left(\mathrm{C}_{17} \mathrm{H}_{19} \mathrm{NO}_{5}\right) \\
\text { Distichamine }\left(\mathrm{C}_{18} \mathrm{H}_{19} \mathrm{NO}_{5}\right)\end{array}$ \\
\hline $\begin{array}{l}M W-1-55 A \\
M W-1-77\end{array}$ & $\begin{array}{l}\text { Euphorbia tirucalli } \\
\text { (Pencil plant) }\end{array}$ & $\begin{array}{l}\text { Latex } \\
\text { Leaves }\end{array}$ & Diterpenoid & $\begin{array}{l}\text { Phorbol }\left(\mathrm{C}_{20} \mathrm{H}_{28} \mathrm{O}_{6}\right) \\
\text { Diterpene }\left(\mathrm{C}_{20} \mathrm{H}_{32}\right)\end{array}$ \\
\hline $\begin{array}{l}M W-1-3 E \\
M W-1-55 B\end{array}$ & $\begin{array}{l}\text { Euphorbia ingens } \\
\text { (Candelabra tree) }\end{array}$ & $\begin{array}{l}\text { Leaves } \\
\text { Latex }\end{array}$ & Diterpenoid & Ingenol $\left(\mathrm{C}_{20} \mathrm{H}_{28} \mathrm{O}_{5}\right)$ \\
\hline MW-1-3D & $\begin{array}{l}\text { Euphorbia virosa } \\
\text { (Poison tree) }\end{array}$ & Latex & Diterpenoid & Diterpene $\left(\mathrm{C}_{20} \mathrm{H}_{32}\right)$ \\
\hline$M W-1-3 B$ & $\begin{array}{l}\text { Strophanthus speciosus } \\
\text { (Poison rope) }\end{array}$ & Seeds & Cardiac glycoside & $\begin{array}{l}\text { Ouabain }\left(\mathrm{C}_{29} \mathrm{H}_{44} \mathrm{O}_{12}\right) \\
\text { Christyoside }\left(\mathrm{C}_{30} \mathrm{H}_{44} \mathrm{O}_{9}\right)\end{array}$ \\
\hline$M W-1-4 B$ & $\begin{array}{l}\text { Strychnos madagascariensis } \\
\text { (Black monkey orange) }\end{array}$ & Unripe seeds & Indole alkaloid & C-toxiferine I $\left(\mathrm{C}_{40} \mathrm{H}_{46} \mathrm{~N}_{4} \mathrm{O}_{2}\right)$ \\
\hline
\end{tabular}

Note: Species listed in bold font are considered to be lethally toxic in relatively small quantities. A complete reference list for the toxic compounds identified in these plants can be found elsewhere. ${ }^{4,12}$ 


\section{Poison on a Hei| |om arrow}

Approximately $2 \mathrm{mg}$ of material was scraped off the 90-year-old Hei | om arrow and added to $1 \mathrm{~mL} \mathrm{DCM}: \mathrm{MeOH}(1: 1)$. The sample was then treated as for the control sample.

\section{Ultra-performance liquid chromatography QTOF mass spectrometry}

Compound separation and detection were performed using a Waters UPLC hyphenated with a Waters Synapt G2 QTOF instrument. The DCM:MeOH dried extracts were reconstituted, first in $100 \%$ acetonitrile followed by water $(0.1 \%$ formic acid) such that the final concentration was $\sim 1 \mathrm{mg} / \mathrm{mL}$ of total crude extract. MS-grade acetonitrile was purchased from Romil. Water with $0.1 \%$ formic acid was purchased from Sigma Aldrich. The extracts were pooled and centrifuged at $10000 \mathrm{~g}$ for $10 \mathrm{~min}$ to remove particulates. Prior to analyses, the instrument was calibrated over a mass range of 50-1200 Da using a sodium formate solution, typically to an absolute mass accuracy of $<0.5 \mathrm{mDa}$ using the Intellistart functionality of the software. The instrument was centrally operated and controlled with MassLynx v4.1 software for data acquisition. A form of data independent analysis termed MSE was used to acquire both low energy (precursor ions) and high energy (product ions) utilising a collision energy ramp from $10 \mathrm{~V}$ to $40 \mathrm{~V}$ over a scan time of $0.3 \mathrm{~s}$. An internal control (the lockspray), namely leucine encephalin, was directly infused into the source through a secondary orthogonal electrospray ionisation probe allowing intermittent sampling (every $10 \mathrm{~s})$. The lockspray was used to compensate for instrument drift, thus ensuring good mass accuracy throughout the duration of the runs. Exactly $5 \mu \mathrm{L}$ of the reconstituted extracts was injected into the UPLC-MS system. All the samples were run in both positive and negative ionisation modes (Table 2).

Table 2: Parameters of the ultra-performance liquid chromatography quadrupole time-of-flight mass spectrometer (UPLC-QTOF-MS) system

\begin{tabular}{l|l}
\hline $\begin{array}{l}\text { Liquid chromatography } \\
\text { system }\end{array}$ & Acquity ${ }^{\circledR}$ \\
\hline Detector & Waters Synapt G2QTOF \\
\hline Calibration mass range & $\begin{array}{l}50-1200 \mathrm{~m} / \mathrm{z} \text { using sodium formate clusters } \\
\text { and Intellistart functionality }\end{array}$ \\
\hline Capillary & $2.8 \mathrm{kV}$ \\
\hline lonisation mode & Electrospray ionisation \\
\hline Source temperature & $100^{\circ} \mathrm{C}$ \\
\hline Sampling cone & $15 \mathrm{~V}$ \\
\hline Extraction cone & $4 \mathrm{~V}$ \\
\hline Desolvation temperature & $200{ }^{\circ} \mathrm{C}$ \\
\hline Cone gas flow & $100 \mathrm{~L} / \mathrm{h}$ \\
\hline Desolvation gas flow & $500 \mathrm{~L} / \mathrm{h}$ \\
\hline Column & Waters C18 BEH, $1.7 \mu \mathrm{m}$ particle size \\
\hline Elution scheme & $\begin{array}{l}30-\mathrm{min} \text { gradient elution scheme from } 98 \% \mathrm{H}_{2} \mathrm{O} \\
(0.1 \% \text { formic acid) to } 100 \% \text { acetonitrile } \\
(0.1 \% \text { formic acid })\end{array}$ \\
\hline Resolution & $\sim 20000 \mathrm{FWHM}$ \\
\hline Absolute mass error & $<0.5 \mathrm{mDa}$ \\
\hline
\end{tabular}

BEH, Ethylene Bridged Hybrid
Separation was completed using a reverse phase step gradient elution scheme from $97 \% \mathrm{H}_{2} \mathrm{O}$ (0.1\% formic acid) to $100 \%$ acetonitrile $(0.1 \%$ formic acid). The column temperature was kept constant at $40^{\circ} \mathrm{C}$ and the flow rate was set at $0.4 \mathrm{~mL} / \mathrm{min}$ for the entire run, giving a total run time of 20 min. A Waters UPLC ${ }^{\circledR} \mathrm{C}_{18}$ Ethylene Bridged Hybrid $1.7 \mu \mathrm{m}$ particle size (2.1 mm ID x $100 \mathrm{~mm}$ length) column was used. Extracted ion chromatograms of the monoisotopic masses for the reported toxic compounds (see Table 1) were obtained from the base peak ion chromatograms to determine the presence of the target compounds in the particular plant sample. The chromatograms indicated the pseudo-molecular ion peak because electrospray ionisation is typically achieved through the addition or removal of one or more protons, i.e. $[\mathrm{M}+\mathrm{H}]^{+}$. The mass of common adducts considered included sodium and potassium in positive mode as well as loss of water, methoxy and acetyl groups. Mass accuracy of precursor ions was used to generate elemental formulae which could then be searched and compared against those in the literature and databases. The acquired isotopic distribution patterns were compared to the proposed elemental formula as further confirmation. In addition, product ion spectra (MS/MS fragments) were obtained for the target compounds from the various plant extracts and blind test samples to further supplement matching of retention time and precursor masses giving a high degree of confidence. Fragmentation patterns of compounds tentatively identified from accurate mass were generated using ChemDraw version 8.0. The fragmentation was used to confirm the MS/MS data.

As a first comparative step, the base peak ion chromatograms of all the samples were overlaid, which allowed visual identification of any obvious common constituents. MarkerLynx and ChromaLynx version 4.1 software was then used to select compound peaks (molecular features possessing a unique retention time-accurate mass pair) from the data matrix through spectral deconvolution algorithms, and to compare similarities and differences among all the samples. The 11 plant extracts and the two poison sample extracts were run in duplicate and only peaks observed in both runs were considered. Method blanks for both the plant extracts and poison samples were run in duplicate for background subtraction purposes.

\section{Results}

\section{Identification of toxins through UPLC-QTOF mass spectrometry}

Known toxins reported in 6 of the 11 plants were tentatively identified based on their accurate mass and MS/MS fragmentations (product ions). However, the occurrence of isomers - structural- and stereoisomers (compounds with the same molecular formula) - makes it difficult to unambiguously identify compounds based on accurate mass and MS/ MS fragmentation. The positive and negative ion chromatograms were obtained for all the plant samples. A selective ion search (extracted ion chromatogram) was done using the monoisotopic mass for the selected toxic compound and possible adducts, as listed in Table 3.

To demonstrate the accuracy and speed in identifying known compounds in complex matrices such as plant extracts, the UPLC positive mode base peak ion chromatogram of an extract of Boophane disticha is shown in Figure 2. The extracted ion chromatograms displaying the compound peaks for distichamine, haemanthamine/crinamine and buphanidrine (and their structures and isotopic distributions) are shown in Figure 3.

\section{Analysis of archaeological samples and control}

Chromatographic overlays of the arrow poison extract and the control recipe extracts were visually compared with all the plant extracts. However, trying to determine areas of overlap proved to be highly complex. The positive and negative base peak ion chromatograms for the extracts of the blind control recipe and arrow poison extracts are shown in Figure $4 \mathrm{a}$ and $4 \mathrm{~b}$, and indicate the complexity of these samples. 
Table 3: Tentative identification of the pseudomolecular ions and adducts of the targeted toxic compounds and compounds not found

\begin{tabular}{|c|c|c|c|c|c|}
\hline Plant & $\begin{array}{l}\text { Toxic compound and molecular } \\
\text { formula }\end{array}$ & Acquired $[\mathrm{M}+\mathrm{H}]+$ & Theoretical $[\mathrm{M}+\mathrm{H}]+$ & $\begin{array}{l}\text { Calculated accurate } \\
\text { mass }(\mathrm{Da})\end{array}$ & Mass error (ppm) \\
\hline Acokanthera oppositifolia & Aglycone of acovenoside $\mathrm{A}\left(\mathrm{C}_{23} \mathrm{H}_{34} \mathrm{O}_{5}\right)$ & 391.2459 & 391.2479 & 390.2406 & 5.1 \\
\hline \multirow{2}{*}{ Adenium multiflorum } & Aglycone of obebioside $B\left(\mathrm{C}_{25} \mathrm{H}_{36} \mathrm{O}_{6}\right)$ & 433.2589 & 433.2584 & 432.2511 & -1.2 \\
\hline & Aglycone of hongheloside $\mathrm{B}\left(\mathrm{C}_{23} \mathrm{H}_{34} \mathrm{O}_{5}\right)$ & 391.2459 & 391.2479 & 390.2406 & 5.1 \\
\hline Aloe gariepensis & $\mathrm{V}$-Coniceine $\left(\mathrm{C}_{8} \mathrm{H}_{15} \mathrm{~N}\right)$ & 126.1293 & 126.1277 & 125.1204 & -12.7 \\
\hline Aloe globuligemma & Coniine $\left(\mathrm{C}_{8} \mathrm{H}_{17} \mathrm{~N}\right)$ & 128.1440 & 128.1434 & 127.1361 & -4.7 \\
\hline \multirow{4}{*}{ Ammocharis coranica } & Lycorine $\left(\mathrm{C}_{16} \mathrm{H}_{17} \mathrm{NO}_{4}\right)$ & 288.1236 & 288.1230 & 287.1157 & -2.1 \\
\hline & Caranine $\left(\mathrm{C}_{16} \mathrm{H}_{17} \mathrm{NO}_{3}\right)$ & 272.1281 & 272.1281 & 271.1208 & 0.0 \\
\hline & Crinamine $\left(\mathrm{C}_{17} \mathrm{H}_{19} \mathrm{NO}_{4}\right)$ & 302.1397 & 302.1387 & 301.1314 & -3.3 \\
\hline & Acetylcaranine $\left(\mathrm{C}_{18} \mathrm{H}_{19} \mathrm{NO}_{4}\right)$ & 314.1395 & 314.1387 & 313.1314 & -2.5 \\
\hline \multirow{5}{*}{ Boophane disticha } & $\begin{array}{l}\text { Distichamine } \\
\left(\mathrm{C}_{18} \mathrm{H}_{19} \mathrm{NO}_{5}\right)\end{array}$ & 330.1343 & 330.1336 & 329.1263 & -2.1 \\
\hline & $\begin{array}{l}\text { Haemanthamine/ Crinamine } \\
\left(\mathrm{C}_{17} \mathrm{H}_{19} \mathrm{NO}_{4}\right)\end{array}$ & 302.1391 & 302.1387 & 301.1314 & -1.3 \\
\hline & Lycorine $\left(\mathrm{C}_{16} \mathrm{H}_{17} \mathrm{NO}_{4}\right)$ & 288.1233 & 288.1230 & 287.1157 & -1.0 \\
\hline & Buphanine/ Buphanidrine $\left(\mathrm{C}_{18} \mathrm{H}_{21} \mathrm{NO}_{4}\right)$ & 316.1544 & 316.1543 & 315.1470 & -0.3 \\
\hline & Crinamidine $\left(\mathrm{C}_{17} \mathrm{H}_{19} \mathrm{NO}_{5}\right)$ & 318.1349 & 318.1336 & 317.1263 & -4.1 \\
\hline
\end{tabular}

Results obtained through UPLC-MS and extracted ion chromatograms.

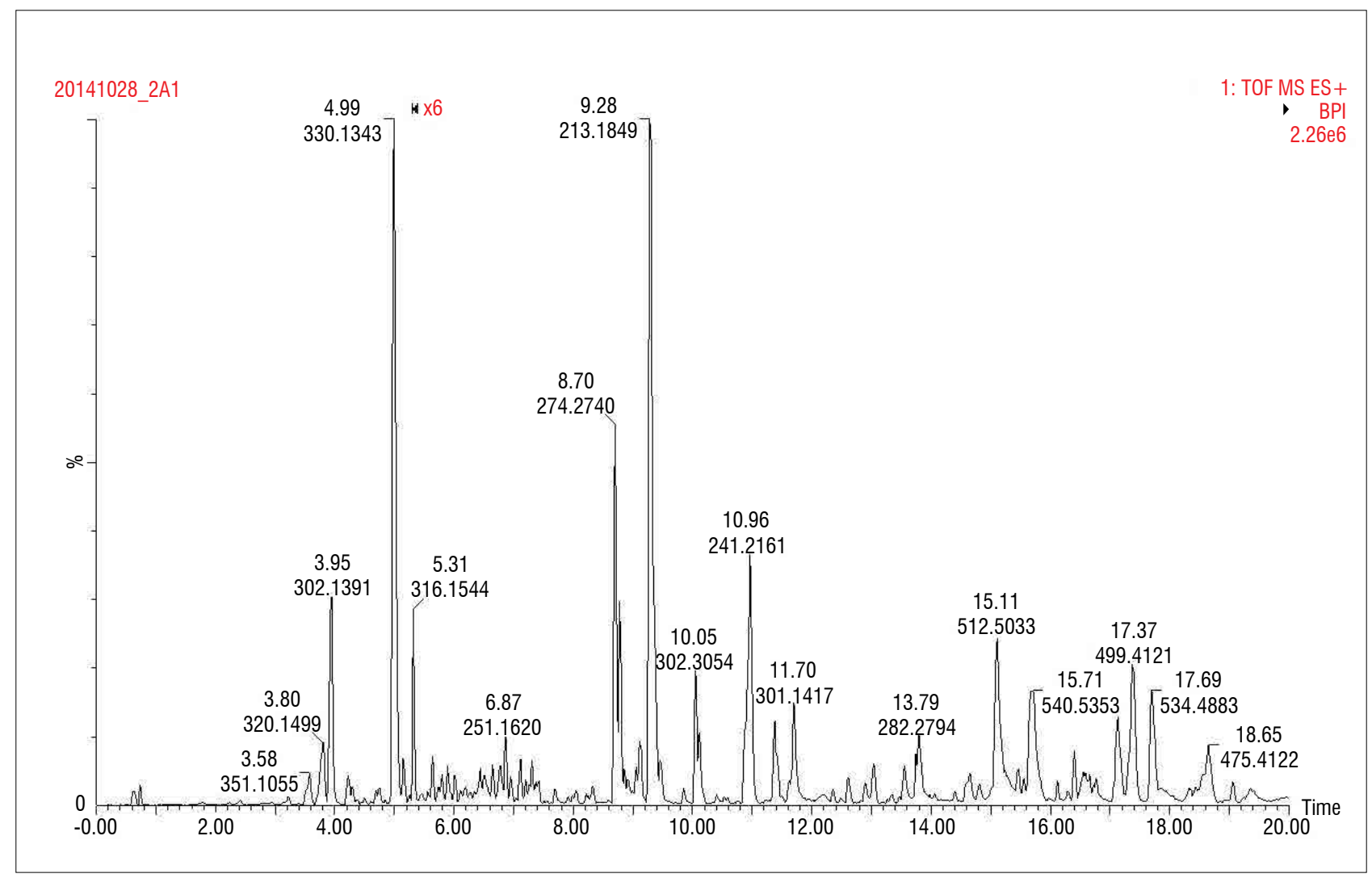

Figure 2: Positive mode base peak ion chromatogram of Boophane disticha. 


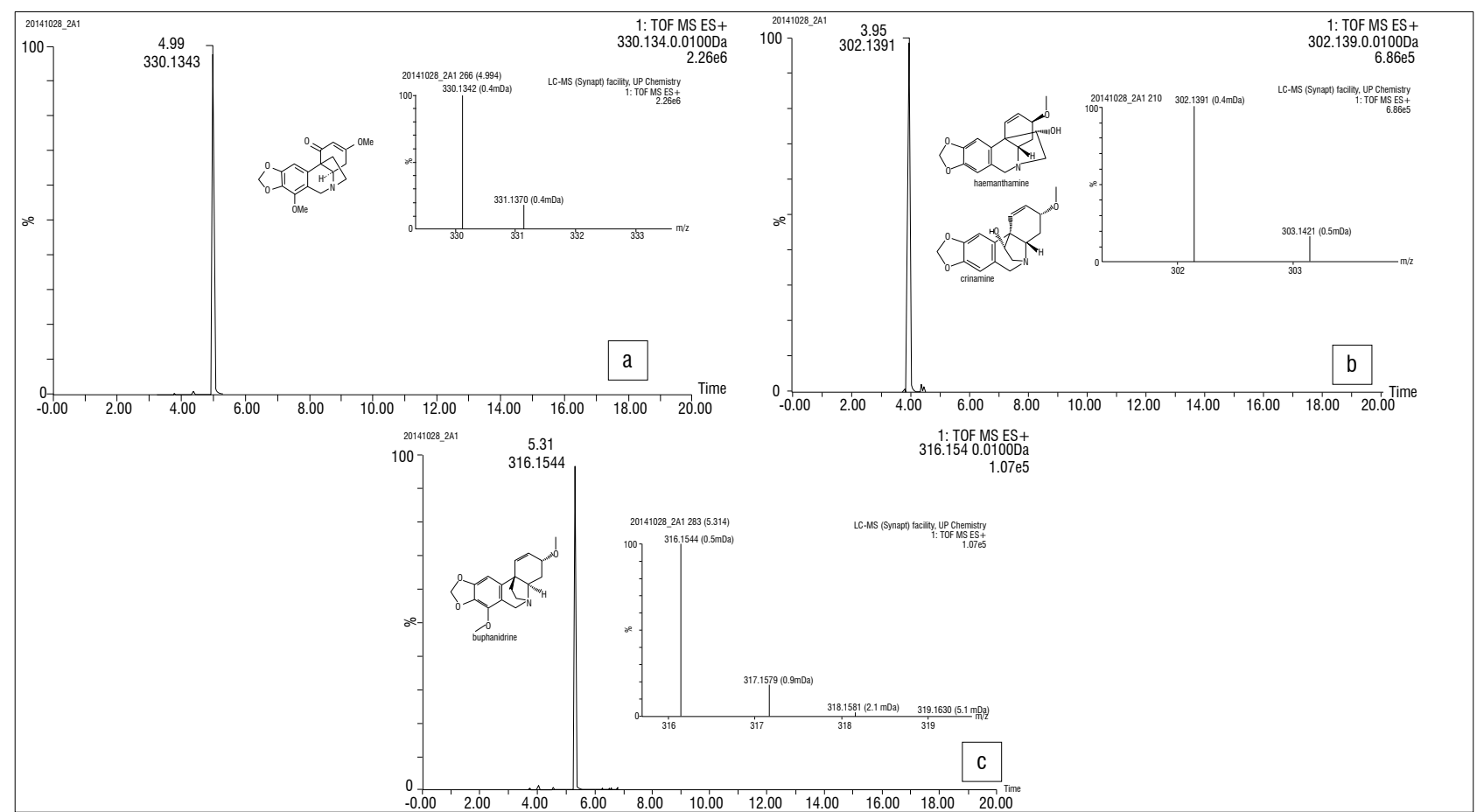

Figure 3: Extracted ion chromatogram from Boophane disticha showing (a) the extracted peak chromatogram of 330.1343 corresponding to the accurate mass of distachamine; (b) the extracted peak chromatogram of 302.1391 corresponding to the accurate mass of stereoisomers haemanthamine and/or crinamine and (c) the extracted peak chromatogram of 316.1544 corresponding to the accurate mass of buphanidrine. The structures and acquired isotopic distribution are shown in the insets.

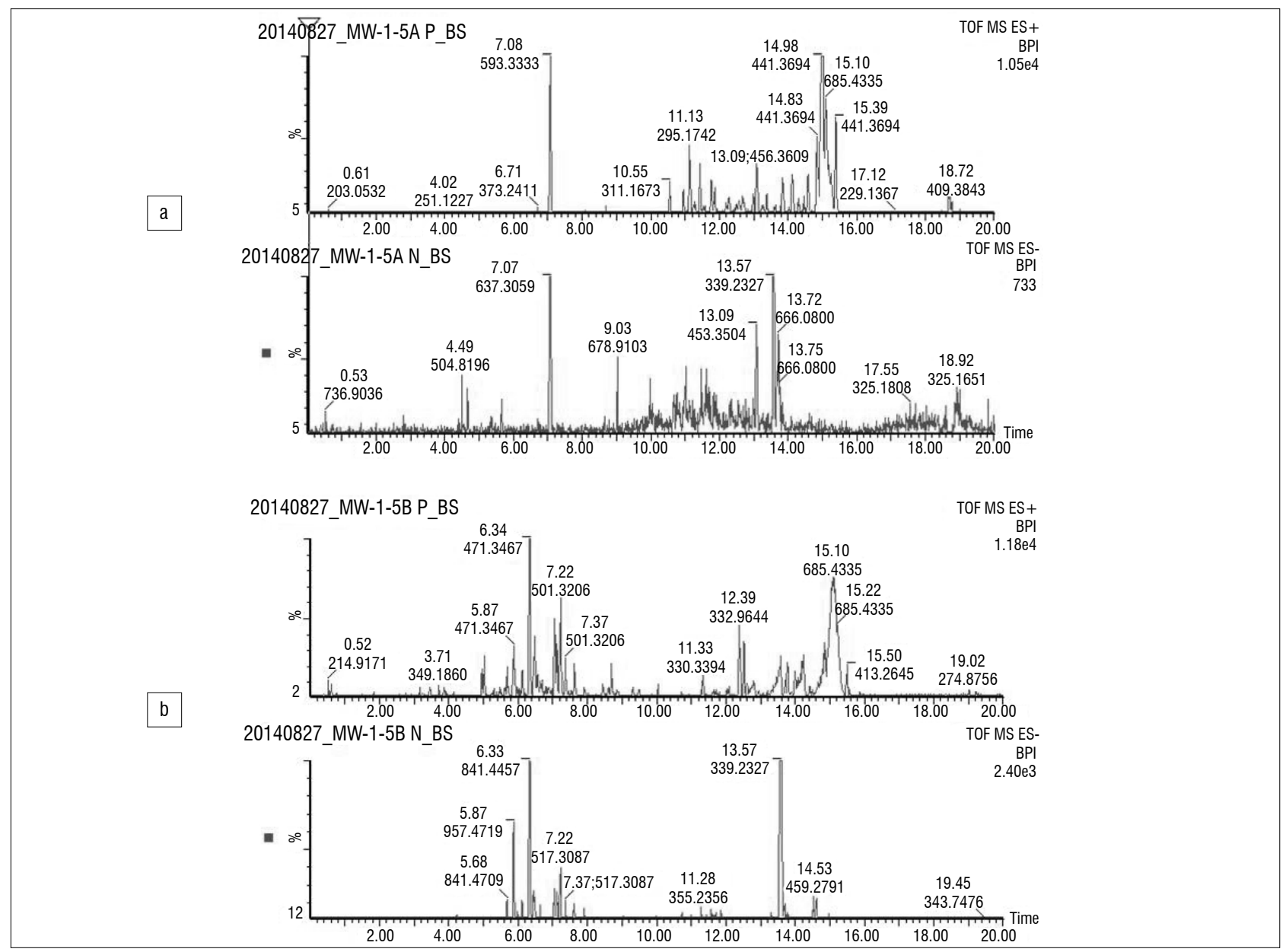

Figure 4: Positive (top) and negative (bottom) base peak ion chromatograms of (a) the control recipe and (b) the Hei | | om arrow poison sample. 
MarkerLynx software was used to identify molecular features (retention time-accurate mass pairs) between all samples and a total of 13049 unique features was identified. The features were compared with ChromaLynx software to identify possible markers (molecular features common amongst a plant extract and a blind sample). Markers with a retention time of $7.04 \mathrm{~min}$ and $\mathrm{m} / \mathrm{z} 1185.6515$ from the extract of A. multiflorum and retention time of $14.49 \mathrm{~min}$ and $\mathrm{m} / \mathrm{z} 967.6968$ from the extract of $E$. tirucalli were both present in the blind control recipe (Figure 5). A marker detected using the software was present in both the blind control sample and $A$. oppositifolia. This compound, however, was not exclusive to these extracts because it was also detected in some of the other plant samples.

The comparison of the chromatographic overlays of the Hei||om arrow poison with all the plant extracts indicated a marker with a pseudomolecular ion, $\mathrm{m} / \mathrm{z} 332.9644$, common to the arrow poison extract and the extract of Strychnos madagascariensis (Figure 6). However, ChromaLynx software analysis revealed the presence of trace amounts of this ion in Strophanthus speciosus, Euphorbia virosa, A. oppositifolia and the control recipe, but not in the sample blank, implying that the Hei | om poison is a compound of plant origin. Although
MS/MS fragmentation was obtained, no conclusive identification of the compound could be made based on the fragmentation patterns. The other compounds that appeared promising as possible markers through visual examination of the chromatograms between the arrow poison and $S$. madagascariensis were eliminated by the MarkerLynx software analysis. Only the compound with $\mathrm{m} / \mathrm{z} 332.9644$ and retention time 12.39 min was identified as a common feature in both the Hei||om poison and $S$. madagascariensis. The fragmentation of this molecular ion was identical between the arrow poison and the $S$. madagascariensis plant sample (Figure 7), providing further evidence of their similarity.

\section{Discussion and conclusions}

Here we report the results of chemical analyses conducted on three sets of material. Firstly, we used extracts from 11 modern plants supplied by the South African National Biodiversity Institute and collected from the Walter Sisulu National Botanical Gardens. Secondly, we created a toxic mixture from three plant extracts and used this mixture as a blind test control. Finally, we analysed the poison on an ethnographic artefact, a Hei| | om arrowhead.

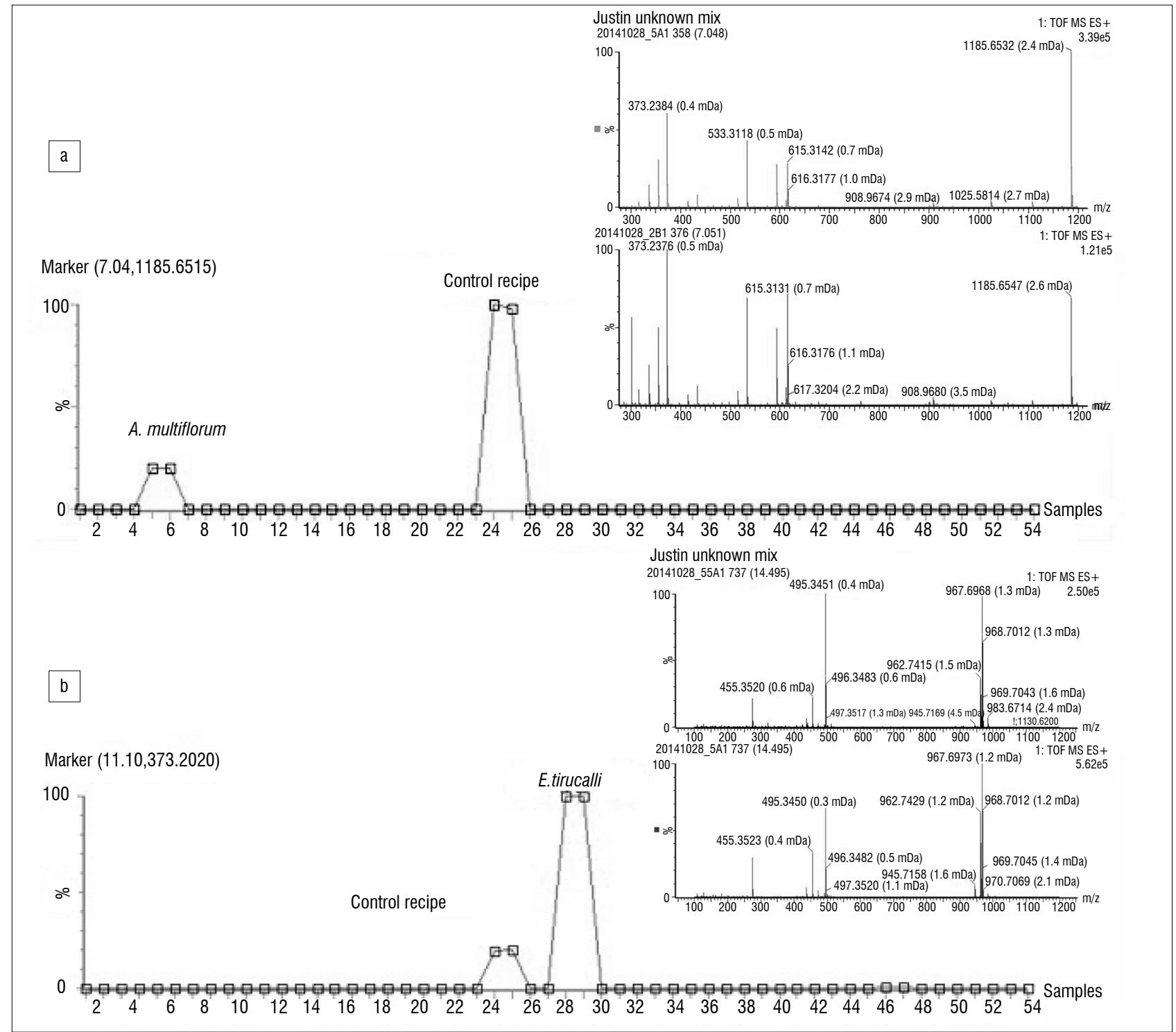

Figure 5: MarkerLynx results showing (a) a marker at $7.04 \mathrm{~min}$ and $\mathrm{m} / \mathrm{z} 1185.6515$ between Adenium multiflorum (sample numbers 5 and 6 ) and the control recipe (sample numbers 24 and 25) and (b) a marker at $14.495 \mathrm{~min}$ and $\mathrm{m} / \mathrm{z} 967.6968$ between Euphorbia tirucalli (sample numbers 28 and 29) and the control recipe (sample numbers 24 and 25). The mass spectra (top right) confirm the presence of a common compound in both extracts. 


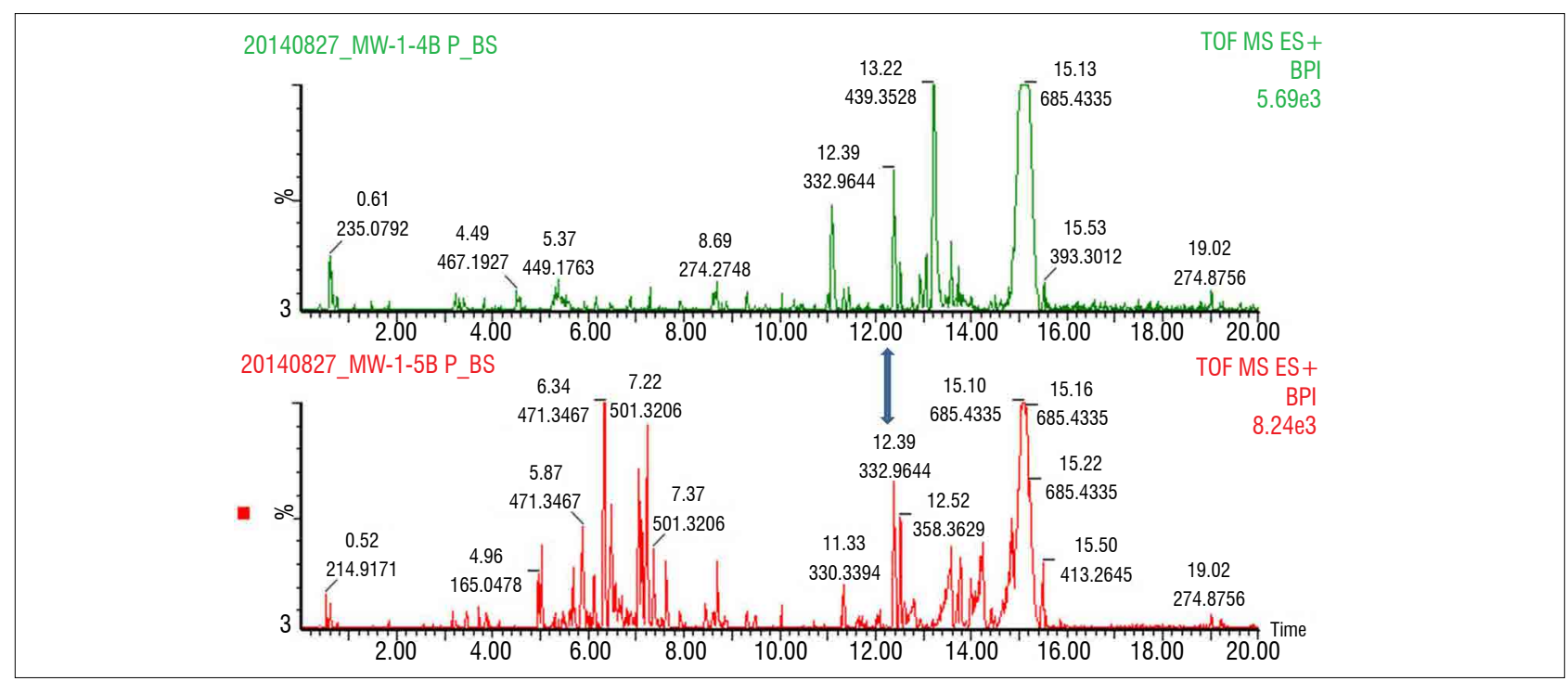

Figure 6: Positive base peak ion chromatograms of Strychnos madagascariensis (top) and the Hei| | om arrow poison (bottom), visually indicating the presence of the common compound with pseudomolecular ion $\mathrm{m} / \mathrm{z} 332$. The molecular ions at retention times $15.10 \mathrm{~min}, \mathrm{~m} / \mathrm{z} 685.4335$, and at $19.02 \mathrm{~min}, \mathrm{~m} / \mathrm{z} 274.8756$, are a result of impurities or are nonspecific to the samples.

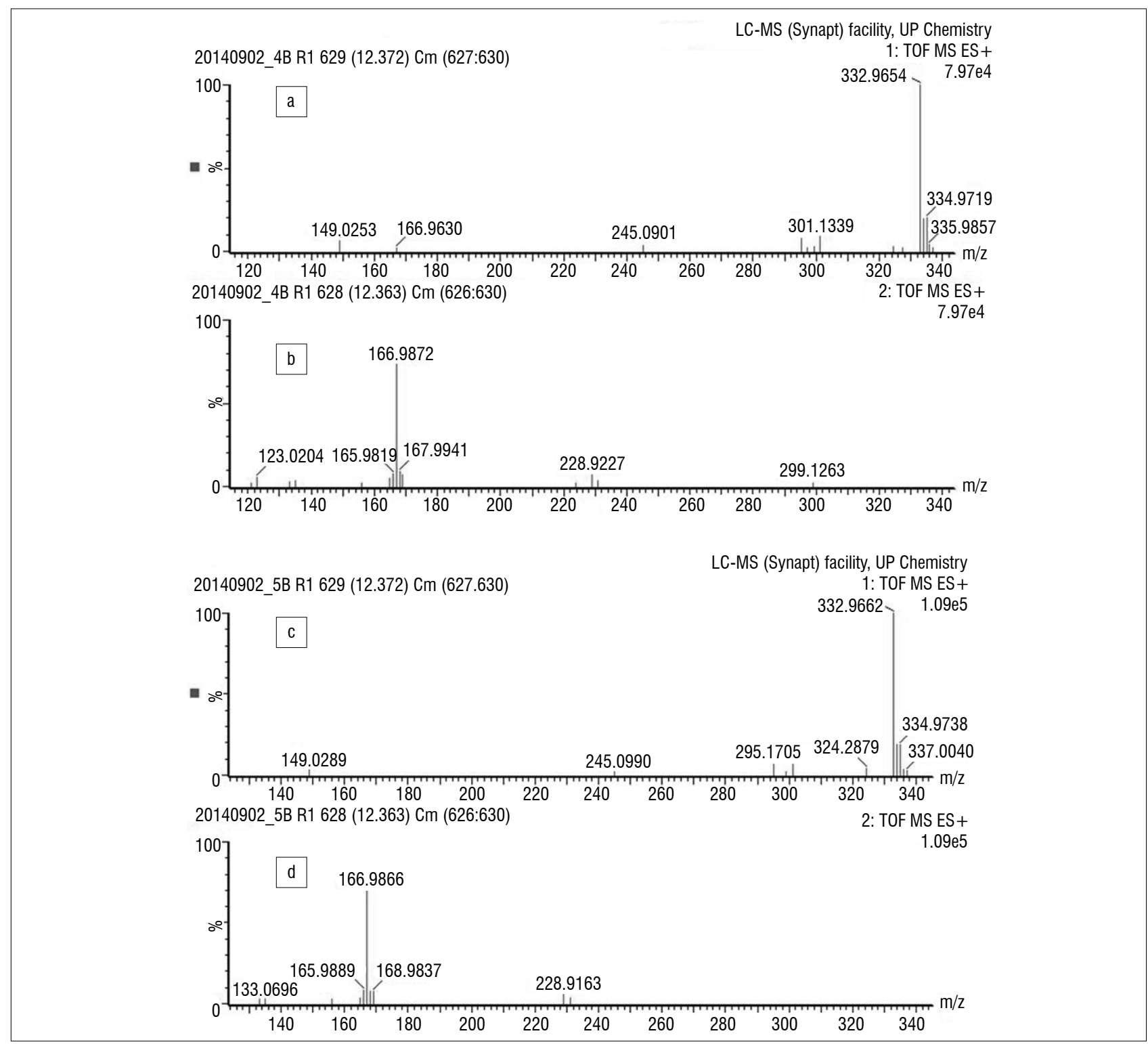

Figure 7: Mass-mass spectrometry fragments for $\mathrm{m} / \mathrm{z} 332.9647$ for (a and b) the Hei | om arrow poison and (c and d) Strychnos madagascariensis extract. 
The results show that our method can be used to tentatively identify toxins based on comparative overlays with fresh plant material, but that no unambiguous associations can be made at this stage. Furthermore, not all expected toxins will be detected, for which there may be several reasons (which are discussed below). The identification of toxic compounds in plants has been typically conducted through the purification and isolation of organic compounds followed by detailed nuclear magnetic resonance analysis to elucidate their structures. This procedure requires large quantities of plant sample and is often a tedious and time-consuming process. This method cannot be used for determining the toxic plant compounds used in arrow poisons because of their small quantities. In order to facilitate the process using limited quantities of arrow poison samples, and to confirm the presence of reported toxins, we have used accurate MS/MS spectrometry. Our aim was to establish whether this technique can be applied to determine the presence of the toxic compounds in both known toxic plants and arrow poisons, which are sometimes mixtures of ingredients from several plants. The UPLC-QTOF-MS technique acquired mass spectral data of the reported toxic compounds in extracts of 11 toxic plants in both the positive and negative mode electrospray ionisation to ensure that most of the compounds were ionised and could be detected. We identified 16 of the 28 reported toxins in 6 of the 11 plants analysed. We did this by comparing the acquired accurate mass with the theoretical accurate mass based on the molecular formula. Further confirmation of the structure was achieved through the MassLynx software which also generated the molecular formula. The toxic compounds identified compared favourably with those in the databases Dictionary of Natural Products and ChemSpider, which report the accurate masses.

All identifications of the toxic compounds were made with high accuracy; they cannot, however, be unambiguously assigned. For unambiguous assignment, full MS/MS fragmentation analysis must be done and then compared to pure standard compounds and/or nuclear magnetic resonance analysis of the pure isolated compounds. Haemanthamine and crinamine, two previously published compounds from $B$. disticha, were identified in the plant extracts. We were unable to determine whether both, or either, were present as they are isomeric forms. The similar assignment problem applies to buphanine and buphandrine present in this plant extract. Two other toxic compounds, lycorine and crinamidine, were also identified in our $B$. disticha extract. Two of three toxins reported in published databases, namely the aglycones of obebioside $B$ and hongheloside $B$, were identified in our $A$. multiflorum extract. All four of the previously published toxins (lycorine, caranine, crinamine and acetylcaranine) were identified in our extract of Ammocharis coranica. However, the two previously published toxins, ouabain and christyoside, could not be identified in our $S$. speciosus extract; $y$-coniceine and coniine were identified from Aloe gariepensis and Aloe globuligemma, respectively, whereas conhydrine, common to both the Aloe species, was not identified. None of the toxic compounds previously published was identified in any of the Euphorbia species we analysed or in our sample of $S$. madagascariensis. Both ouabain and acovenoside A were identified in the highly toxic plant $A$. oppositifolia. The non-identification of toxic compounds in some of our plant extracts may be attributed to the geographical area in which the plants were collected. It is known that plant species display a variation in their secondary metabolites as a consequence of the environmental conditions and geographical location in which they are grown and the season in which they are harvested. ${ }^{37}$ In addition, the generic extraction methodology and the use of MS friendly aqueous solvents (and additives) may have excluded them according to their solubility, or inhibited their preferred ionisation in negative mode.

To assess the feasibility of the method, we applied the UPLC-QTOF-MS approach to the detection of plant-based poisonous compounds in a control sample in which three plant extracts were mixed. Two of the three plants used in the control sample poison were correctly identified as A. multiflorum and E. tirucalli, based on unique markers, namely $\mathrm{m} / \mathrm{z}$ 1185.6532 and 967.6968. Indiscriminate markers that are present in several plants were found in the control sample as well as in the extract of $A$. oppositifolia. This finding is not unusual as the same chemical compounds can occur in several different plant species.
The UPLC-QTOF-MS results of the Hei||lom arrow poison were visually compared to chromatograms of the plants analysed with the aid of chromatographic overlays followed by analysis with MarkerLynx and ChromaLynx software. A marker with a pseudomolecular ion $\mathrm{m} / \mathrm{z}$ 332.9650 was common to the Hei| | om arrow extract and the extract of S. madagascariensis. ChromaLynx software analysis, however, revealed the presence of trace amounts of this ion in S. speciosus, E. virosa, A. oppositifolia and the control recipe. Although S. madagascariensis is not present in the region from which the arrow is thought to have come, it may be that the poisonous ingredient or the arrow itself was originally obtained through exchange from farther afield. Ideally, other species of Strychnos, such as the $S$. spinosa, should be collected and similarly analysed. It is encouraging that we were able to get chemical signatures from small samples and that there are clearly identifiable plant-based toxins detectable in poisons created more than 90 years ago. This bodes well for future work on ethnographic and archaeological material, despite the various challenges. These challenges include the limited quantities of arrow poison samples likely to be available for analysis from archaeologically recovered artefacts, and harsh post-depositional conditions that may have caused degradation of organic residues. Several other factors such as the variation of secondary metabolites between wild and cultivated plants, chemical variation between species, the production of certain classes of compounds being restricted to a specific plant part (e.g. roots, leaves), and the solvents used for the extraction of toxic compounds, all play an influential role and have to be taken into consideration.

\section{Acknowledgements}

Most of the plant material was supplied by the South African National Biodiversity Institute and we thank Andrew Hankey of the Walter Sisulu National Botanical Gardens for his assistance in this regard. Diana Wall of Museum Africa provided access to the Fourie Collection and other poisoned arrows. The financial assistance of the National Research Foundation of South Africa towards this research is hereby acknowledged. Opinions expressed and conclusions arrived at, are those of the authors and are not necessarily to be attributed to the National Research Foundation.

\section{Authors' contributions}

J.B. and M.L. conceptualised the project; M.W. and D.K. prepared and ran the samples; V.M. interpreted the results; M.W., J.B. and V.M. wrote the paper; D.K. and M.W. prepared the figures; D.K., L.W. and M.L. provided academic input; and L.W. and L.P. provided conceptual input and read the draft manuscript.

\section{References}

1. Schapera I. Bushman arrow poisons. Bantu Studies. 1925;2:199-214. https://doi.org/10.1080/02561751.1923.9676184

2. Lee R. The !Kung San: Men, women and work in a foraging society. Cambridge: Cambridge University Press; 1979.

3. Marshall-Thomas E. The old way: A story of the first people. New York: Farrar, Straus and Giroux; 2006.

4. Bradfield J, Wadley L, Lombard M. Southern African arrow poison recipes, their ingredients and implications for Stone Age archaeology. South Afr Humanities. 2015;27:29-66.

5. Wadley L, Trower G, Backwell L, d'Errico F. Traditional glue, adhesive and poison used for composite weapons by Ju/'hoan San in Nyae Nyae, Namibia. Implications for the evolution of hunting equipment in prehistory. PLOS ONE. 2015;10(10), e0140269. https://doi.org/10.1371/journal.pone.0140269

6. Chaboo C, Biesele M, Hitchcock R, Weeks A. Beetle and plant arrow poisons of the Ju|'hoan and Hai| | om San peoples of Namibia (Insecta, Coleoptera, Chrysomelidae, Plantae, Anacardiaceae, Apocynaceae, Burseraceae). ZooKeys. 2016;558:9-54. https://doi.org/10.3897/zookeys.558.5957

7. Mebs D, Brüning F, Pfaff N, Neuwinger H. Preliminary studies on the chemical properties of the toxic principle from Diamphidia nigro-ornata larvae, a source of Bushmen arrow poison. J Ethnopharmacol. 1982;6:1-11. https:// doi.org/10.1016/0378-8741(82)90068-X 
8. Woollard J, Fuhrman F, Mosher H. The Bushman arrow toxin, Diamphidia toxin: Isolated from pupae of Diamphidia nigro-ornata. Toxicon. 1984;22:937-946. https://doi.org/10.1016/0041-0101(84)90185-5

9. Kao C, Salwen M, Hu S, Pitter H, Woollard J. Diamphidia toxin, the Bushman's arrow poison: Possible mechanism of prey killing. Toxicon. 1989;27:13511366. https://doi.org/10.1016/0041-0101(89)90067-6

10. Jacobsen T, Sand O, Bjøro T, Karlsenz H, Iversen J-G. Effect of Diamphidia toxin, a Bushman arrow poison, on ionic permeability in nucleated cells. Toxicon. 1990;28:435-444. https://doi.org/10.1016/0041-0101(90)90082-I

11. Watt J, Breyer-Brandwijk M. The medicinal and poisonous plants of southern and eastern Africa. London: Livingstone Press; 1962.

12. Neuwinger H. African ethnobotany: Poisons and drugs: Chemistry, pharmacology, toxicology. New York: Chapman \& Hall; 1996.

13. Marshall L. !Kung Bushman bands. Africa: Journal of the International Institute. 1960;30:325-355. https://doi.org/10.2307/1157596

14. Wadley L. The invisible meat providers: Women in the Stone Age of South Africa. In: Kent S, editor. Gender in African prehistory. Altamira: Walnus Creek; 1998. p. 69-81.

15. d'Errico F, Backwell L, Villa P, Degano I, Lucejko J, Bamford M, et al. Early evidence of San material culture represented by organic artefacts at Border Cave, South Africa. Proc Natl Acad Sci USA. 2012;109:13214-13219. https://doi.org/10.1073/pnas.1204213109

16. Lombard M, Haidle M. Thinking a bow-and-arrow set: Cognitive implications of Middle Stone Age bow and stone-tipped arrow technology. Camb Archaeol J. 2012;22:237-264. https://doi.org/10.1017/S095977431200025X

17. Williams V, Burke A, Lombard M. Throwing spears and shooting arrows: Preliminary results of a pilot neuroarchaeological study. S Afr Archaeo Bull. 2014;69:199-207.

18. Robbins L, Campbell A, Brook G, Murphy M, Hitchcock R. The antiquity of the bow and arrow in the Kalahari Desert: Bone points from White Paintings Rock Shelter, Botswana. J Afr Archaeol. 2012;10:7-20. https://doi. org/10.3213/2191-5784-10211

19. Backwell L, d'Errico F, Wadley L. Middle Stone Age bone tools from the Howiesons Poort layers, Sibudu Cave, South Africa. J Archaeol Sci. 2008;35:1566-1580. https://doi.org/10.1016/j.jas.2007.11.006

20. Lombard M, Phillipson L. Indications of bow and stone-tipped arrow use 64 000 years ago in KwaZulu-Natal, South Africa. Antiquity. 2010;84:635-648. https://doi.org/10.1017/S0003598X00100134

21. Lombard M. Quartz-tipped arrows older than 60 ka: Further use-trace evidence from Sibudu, KwaZulu-Natal, South Africa. J. Archaeol Sci. 2011; 38: 1918-1930. https://doi.org/10.1016/.j.jas.2011.04.001
22. Wadley L, Mohapi M. A segment is not a monolith: Evidence from the Howiesons Poort of Sibudu, South Africa. J Archaeol Sci. 2008:35:25942605. https://doi.org/10.1016/.j.jas.2008.04.017

23. Pargeter J, Shea J, Utting B. Quartz backed tools as arrowheads and hand-cast spearheads: Hunting experiments and macro-fracture analysis. J Archaeol Sci. 2016;73:145-157. http://dx.doi.org/10.1016/j.jas.2016.08.001

24. Wadley L, Sievers C, Bamford M, Goldberg P, Berna F, Miller C. Middle Stone Age bedding construction and settlement patterns at Sibudu, South Africa. Science. 2011;334:1388-1391. https://doi.org/10.1126/science.1213317

25. Borgia V, Carlin M, Crezzini J. Poison, plants and palaeolithic hunters. An analytical method to investigate the presence of plant poison on archaeological artefact. Quatern Int. 2017;427(B):94-103. https://doi.org/10.1016/j. quaint.2015.12.025

26. Van Wyk B-E, Van Heerden F, Van Oudshoorn B. Poisonous plants of South Africa. Pretoria: Briza Publications; 2002.

27. Taiz L, Zeiger E. Plant physiology. Sunderland, MA: Sinauer Associates; 2010.

28. Bisset N. Arrow and dart poisons. J Ethnopharmacol. 1989;25:1-41. https:// doi.org/10.1016/0378-8741(89)90043-3

29. Van Wyk B-E, Van Oudtshoorn B, Gericke N. Medicinal plants of South Africa. Pretoria: Briza Publications; 1997.

30. Philippe G, Angenot L. Recent developments in the field of arrow and dart poisons. J Ethnopharmacol. 2005;100:85-91. https://doi.org/10.1016/j. jep.2005.05.022

31. Shaw M, Woolley P, Rae F. Bushmen arrow poisons. Cimbebasia. 1963;7:241.

32. Langejans GHJ. Remains of the day - Preservation of organic micro-residues on stone tools. J Archaeol Sci. 2010;37:971-985. https://doi.org/10.1016/j. jas.2009.11.030

33. Fourie L. Preliminary notes on certain customs of the Hei-//om Bushmen. Journal of the South West Africa Scientific Society. 1926;1:49-63.

34. Fourie L. The Bushmen of South West Africa. In: Hahn C, editor. The native tribes of South West Africa. London: Frank Cass; 1928. p. 81-105.

35. Wanless A. The silence of colonial melancholy: The Fourie collection of Khoisan ethnologica [PhD thesis]. Johannesburg: University of the Witwatersrand; 2007.

36. Bradfield J. Macrofractures on bone-tipped arrows: Analysis of hunter-gatherer arrows in the Fourie collection from Namibia. Antiquity. 2012;86:1179-1191. https://doi.org/10.1017/S0003598X0004833X

37. Pavarini D, Pavarini S, Niehues M, Lopes N. Exogenous influences on plant secondary metabolite levels. Anim Feed Sci Tech. 2012;176:5-16. https:// doi.org/10.1016/i.anifeedsci.2012.07.002 